\title{
Validation of a Three-Item Short Form of the Modified Weight Bias Internalization Scale (WBIS-3) in the German Population
}

\author{
Sören Kliem ${ }^{a}$ Hans-Christian Puls $^{c, d} \quad$ Andreas Hinz $^{b} \quad$ Anette Kersting $^{c}$ \\ Elmar Brähler ${ }^{c-e}$ Anja Hilbert ${ }^{c, d}$ \\ ${ }^{a}$ Ernst-Abbe-Hochschule, University of Applied Sciences, Jena, Germany; ${ }^{b}$ Department \\ of Medical Psychology and Medical Sociology, University of Leipzig, Leipzig, Germany; \\ 'Department of Psychosomatic Medicine and Psychotherapy, University of Leipzig, \\ Leipzig, Germany; ${ }^{\mathrm{d} I n t e g r a t e d ~ R e s e a r c h}$ and Treatment Center AdiposityDiseases, \\ Behavioral Medicine Research Unit, University of Leipzig Medical Center, Leipzig, Germany; \\ e Department of Psychosomatic Medicine and Psychotherapy, University Medical Center of \\ the Johannes Gutenberg University of Mainz, Mainz, Germany
}

\section{Keywords}

Social perception · Bias · Overweight · Obesity · Epidemiologic studies · Psychometrics

\begin{abstract}
Introduction: Individuals suffering from overweight or obesity frequently experience weightbased stigmatization. The widespread belief that weight is a matter of personal will and selfcontrol results in various weight-based stereotypes (e.g., laziness, lack of self-discipline, or neglect). Objective: Based on the modified version of the Weight Bias Internalization Scale (WBIS-M), a short form for the economic assessment of weight bias internalization in the general population was compiled and validated. Methods: A three-item short form (WBIS-3) was derived based on data from a representative sample of the German population $(n=1,092)$. This new short form was validated in a second representative population sample $(n=2,513)$. Item characteristics and internal consistency were obtained. Measurement invariance was tested. Construct validity was established via the correlation with theoretically related constructs (depression, anxiety, eating behavior, discrimination, weight status). To establish scale validity, all analyses were performed for the whole sample as well as for the subsample of individuals with overweight. Age- and gender-specific population norms were provided. $\boldsymbol{R e}$ sults: The WBIS-3 exhibited excellent psychometric properties. Internal consistency was $\alpha=$ 0.92. Strong measurement invariance was confirmed regarding age, gender, discrimination, and weight status in both the whole sample as well as the overweight subsample. Conclu-
\end{abstract}


sions: The WBIS-3 constitutes a valid and economical tool for the assessment of weight bias internalization in epidemiological contexts. Measurement invariance allows for an unbiased comparison of means, correlation coefficients, and path coefficients within structural equation modeling across groups.

(C) 2020 The Author(s)

Published by S. Karger AG, Basel

\section{Introduction}

Individuals suffering from overweight or obesity frequently experience weight-based stigmatization [1-5]. The widespread belief that weight is a matter of personal will and selfcontrol [6] results in various weight-based stereotypes (e.g., laziness, lack of self-discipline or neglect). Weight bias internalization (WBI) is a relatively new concept in health psychology research. It is characterized by adopting a negative bias, that is, negative weight stereotypes and applying them to oneself $[7,8]$. Recent reviews $[9,10]$ highlighted the relationship between WBI and various adverse health consequences such as binge eating, decreased physical activity, psychological distress including depression, weight gain, and obesity.

In light of an increasing prevalence of overweight and obesity and given high WBI rates among individuals with overweight $[11,12]$, epidemiological research of this phenomenon is warranted. However, most WBI assessment tools (e.g., Weight Bias Internalization Scale [7, 13] or Weight Self-stigma Questionnaire [14]) include the term "overweight" in almost every item, limiting their application to individuals who are either objectively or subjectively overweight [15]. Consequently, the samples used in WBI research are often highly selective and predominantly include female individuals receiving treatment for overweight or related disorders. Results from broader epidemiological surveys could further enrich our understanding of WBI in the general population.

This study addressed the development and validation of WBIS short form for use in epidemiological surveys with the following properties: (i) incorporating a neutral wording for assessment across various body weight categories as recommended by Pearl and Puhl [13] in their modified version of the Weight Bias Internalization Scale (WBIS-M); (ii) a manageable length, minimizing questionnaire burden while maintaining correspondence with the long form and reliability; and (iii) measurement invariance which is relevant given the selectivity of previous samples, especially regarding gender and weight status.

\section{Materials and Methods}

The short form development comprised two phases. In phase 1, items were selected based on a representative survey from Hilbert et al. [11]. In phase 2, the short form was validated in a different representative population sample. Both sampling procedures were identical. Sample information for both phases can be obtained from Table 1.

\section{Short Form Development}

Items for the short form were selected according to the following criteria: (i) high coefficient alpha, (ii) unidimensionality for a meaningful sum score interpretation, (iii) adequate coverage of the construct, (iv) high correlation with the total scale, and (v) economical number of items. The scale shortening algorithm alphamax [16] was applied to suggest combinations of items with optimal coefficient alpha. In a second step, potential abbreviated item sets were compared using confirmatory factor analyses (CFA). Based on these analyses, a subset consisting of item 3 ("I feel anxious about my weight because of what people might think of me."), 5 ("Whenever I

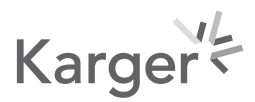


Table 1. Sample characteristics (phase 1: $n=1,092$ and phase 2: $n=2,513$ )

\begin{tabular}{|c|c|c|c|c|c|c|}
\hline & \multirow{2}{*}{\multicolumn{2}{|c|}{$\begin{array}{l}\text { Phase } 1 \\
\text { Overweight subsample }\end{array}$}} & \multicolumn{4}{|l|}{ Phase 2} \\
\hline & & & \multicolumn{2}{|l|}{ Full sample } & \multicolumn{2}{|c|}{ Overweight subsample } \\
\hline & $\begin{array}{l}\text { Women } \\
(n=514), \\
n(\%)\end{array}$ & $\begin{array}{l}\text { Men } \\
(n=578), \\
n(\%)\end{array}$ & $\begin{array}{l}\text { Men } \\
(n=1,119), \\
n(\%)\end{array}$ & $\begin{array}{l}\text { Women } \\
(n=1,394), \\
n(\%)\end{array}$ & $\begin{array}{l}\text { Men } \\
(n=609), \\
n(\%)\end{array}$ & $\begin{array}{l}\text { Women } \\
(n=622), \\
n(\%)\end{array}$ \\
\hline \multicolumn{7}{|l|}{ Age, years } \\
\hline$\leq 24$ & $25(4.9)$ & $32(5.5)$ & $140(12.5)$ & $137(9.8)$ & $42(6.9)$ & $24(3.9)$ \\
\hline $25-34$ & $58(11.3)$ & $51(8.8)$ & $159(14.2)$ & $218(15.6)$ & $60(9.9)$ & $80(12.9)$ \\
\hline $35-44$ & $61(11.8)$ & $75(13.0)$ & $166(14.8)$ & $208(14.9)$ & $104(17.1)$ & $85(13.7)$ \\
\hline $45-54$ & $87(16.9)$ & $113(19.6)$ & $197(17.6)$ & $274(19.7)$ & $120(19.7)$ & $130(20.9)$ \\
\hline $55-64$ & $133(25.9)$ & $133(23.0)$ & $216(19.3)$ & $245(17.6)$ & $141(23.2)$ & $132(21.2)$ \\
\hline $65-74$ & $99(19.3)$ & $142(24.6)$ & 155 (13.9) & $192(13.8)$ & $103(16.9)$ & $115(18.5)$ \\
\hline$\geq 75$ & $51(9.9)$ & $32(5.5)$ & $86(7.7)$ & $120(8.6)$ & $39(6.4)$ & $56(9.0)$ \\
\hline \multicolumn{7}{|l|}{ Weight status ${ }^{\mathrm{a}}$} \\
\hline Underweight $\left(<18.5 \mathrm{~kg} / \mathrm{m}^{2}\right)$ & - & - & $4(0.4)$ & $30(2.2)$ & - & - \\
\hline Normal weight $\left(18.5-24.99 \mathrm{~kg} / \mathrm{m}^{2}\right)$ & - & - & $506(45.2)$ & $742(53.2)$ & - & - \\
\hline Overweight (25.0-29.99 kg/m²) & $392(76.3)$ & $478(82.7)$ & $466(41.6)$ & $404(29.0)$ & $466(76.5)$ & $404(65.0)$ \\
\hline Obesity $\left(\geq 30.0 \mathrm{~kg} / \mathrm{m}^{2}\right)$ & $122(23.7)$ & $100(17.3)$ & $143(12.8)$ & $218(15.6)$ & $143(23.5)$ & $218(35.0)$ \\
\hline \multicolumn{7}{|l|}{ Education, years } \\
\hline$<12$ & $464(90.3)$ & $473(81.8)$ & $878(78.5)$ & $1,116(80.1)$ & $112(18.4)$ & $81(13.0)$ \\
\hline$\geq 12$ & $50(9.7)$ & $105(18.2)$ & $241(21.5)$ & $278(19.9)$ & $497(81.6)$ & $541(87.0)$ \\
\hline \multicolumn{7}{|l|}{ Household income } \\
\hline$<1,000$ (EUR/month) & $51(10.0)$ & $34(6.0)$ & $75(6.9)$ & $142(10.6)$ & $36(6.2)$ & $58(9.6)$ \\
\hline$\geq 1,000$ (EUR/month) & $458(90.0)$ & $534(94.0)$ & $1,005(93.1)$ & $1197(89.4)$ & $549(93.8)$ & $544(90.4)$ \\
\hline \multicolumn{7}{|l|}{ Marital status } \\
\hline Married & $269(52.3)$ & $363(62.8)$ & $554(49.6)$ & $604(43.5)$ & $346(56.9)$ & $296(47.7)$ \\
\hline Single, divorced, widowed & $245(47.7)$ & 215 (37.2) & $562(50.4)$ & $784(56.5)$ & $262(43.4)$ & 325 (52.3) \\
\hline \multicolumn{7}{|l|}{ Nationality } \\
\hline German & $509(99.0)$ & 566 (97.9) & $1,081(96.6)$ & $1,346(96.6)$ & $592(97.2)$ & 604 (97.1) \\
\hline Other & $5(1.0)$ & $12(2.1)$ & $38(3.4)$ & $48(3.4)$ & $17(2.8)$ & 18 (2.9) \\
\hline
\end{tabular}

think a lot about my weight, I feel depressed."), and 6 ("I hate myself for my weight.") was deemed appropriate. It showed an excellent internal consistency $(\alpha=0.90)$ and a very strong correlation with the WBIS total score $(r=0.94 ; p<0.001)$. The original 7-point rating scale was kept.

\section{Sampling}

Data were collected as part of a representative survey. Sampling in both phases was conducted in three stages. First, 258 areas in Germany were chosen. In a second step, within the chosen areas the target households were randomly selected, using random route procedures. Finally, the target person within the household was determined with a Kish selection grid. All participants provided written informed consent.

\section{Participants}

In the validation sample (phase 2), $n=2,513$ individuals were assessed (55.5\% female), corresponding to a response rate of $51.9 \%$ (contacted households: $n=4,844$ ). The participants' age ranged from 14 to 94 years $(M=48.79, S D=18.10)$ with a body mass index (BMI) derived from self-reported weight and height ranged from 15.55 to $67.06 \mathrm{~kg} / \mathrm{m}^{2}(\mathrm{M}=25.81$ $\mathrm{kg} / \mathrm{m}^{2}, \mathrm{SD}=4.99$ ). 


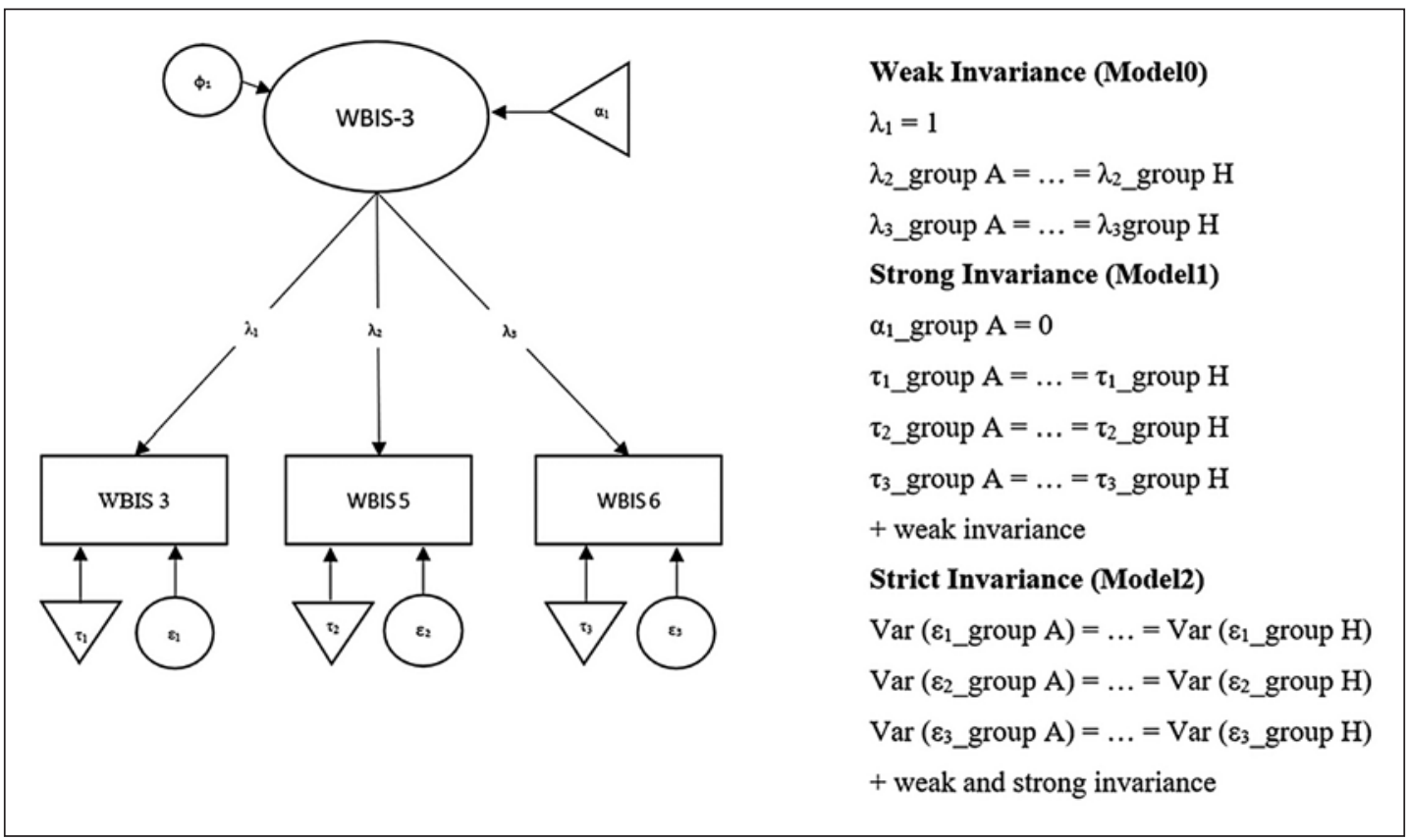

Fig. 1. Explanation of the different models regarding measurement invariance analysis.

\section{Measures for Validation}

Major depression was assessed with the Patient Health Questionnaire PHQ-2 [17], German version [18]. This 2-item self-administered version of the PRIME-MD [19] covers both DSM-5 main criteria for major depression. Anxiety was assessed with the Generalized Anxiety Disorder Scale-2 (GAD-2) [20], German version [21]. It covers the presence of the two main symptoms of generalized anxiety disorder 2 weeks prior to assessment. Disturbed eating (restrained eating, external eating, and emotional eating) was assessed with the Dutch Eating Behaviour Questionnaire [22] (DEBQ, German version [23]) comprising 33 items. Weight-related discrimination was assessed using three items capturing the personal encounters with weight bias [24] (e.g., being teased) using a 5-point scale ranging from "never" to "very often". The number of endorsed items (i.e., answers other than "never") was used as an indicator of discrimination.

\section{Statistical Analyses}

Missing values (on item-level: $0.1-0.7 \%$ ) were imputed using the R package mice with chained equation modeling [25] based on gender and age. To avoid non-existing item values, the estimated values $(\hat{y})$ were corrected by predictive mean matching.

\section{Item Analysis}

The following item characteristics were evaluated: (1) item mean and standard deviation, (2) item-rest correlation, and (3) item difficulty.

To replicate well-established associations from WBI research, correlation coefficients with depression (PHQ-2), anxiety (GAD-2), and eating behavior (DEBQ) were examined, testing the following hypotheses: (1) higher WBI should be associated with higher depression, anxiety, and discrimination $[6,17,18]$; (2) higher WBI should be associated with higher levels of the DEBQ [26]. 
Table 2. Item characteristics of the total sample and the overweight subsample

\begin{tabular}{|c|c|c|c|c|c|c|c|c|c|c|c|c|c|c|}
\hline \multirow[t]{2}{*}{ Item } & & \multicolumn{4}{|c|}{$\begin{array}{l}\text { Total sample } \\
(n=2,513, \alpha=0.92)\end{array}$} & \multicolumn{4}{|c|}{$\begin{array}{l}\text { Men } \\
(n=1,119, \alpha=0.92)\end{array}$} & \multicolumn{4}{|c|}{$\begin{array}{l}\text { Women } \\
(n=1,394, \alpha=0.91)\end{array}$} & \multirow[t]{2}{*}{$d$} \\
\hline & & $M$ & $S D$ & $p v$ & $r_{\text {it }}$ & $M$ & $S D$ & $p$ value & $r_{\text {it }}$ & $M$ & $S D$ & $p v c$ & $r_{\mathrm{it}}$ & \\
\hline \multirow[t]{3}{*}{ Item } & 3 & 1.73 & 1.33 & 12 & 0.83 & 1.53 & 1.1 & 9 & 0.84 & 1.9 & 1.47 & 15 & 0.83 & -0.28 \\
\hline & 5 & 1.82 & 1.45 & 14 & 0.87 & 1.56 & 1.19 & 9 & 0.88 & 2.03 & 1.61 & 17 & 0.86 & -0.33 \\
\hline & 6 & 1.56 & 1.21 & 9 & 0.8 & 1.39 & 0.96 & 7 & 0.82 & 1.71 & 1.36 & 12 & 0.79 & -0.27 \\
\hline \multirow{2}{*}{\multicolumn{2}{|c|}{ WBIS-3 sum score }} & 5.12 & 3.7 & 12 & - & 4.47 & 3.03 & 8 & - & 5.63 & 4.1 & 15 & - & -0.32 \\
\hline & & \multicolumn{4}{|c|}{$\begin{array}{l}\text { Individuals with overweight } \\
(n=1,231, \alpha=0.91)\end{array}$} & \multicolumn{4}{|c|}{$\begin{array}{l}\text { Men with overweight } \\
(n=609, \alpha=0.92)\end{array}$} & \multicolumn{4}{|c|}{$\begin{array}{l}\text { Women with overweight } \\
(n=622, \alpha=0.91)\end{array}$} & $d$ \\
\hline \multirow[t]{3}{*}{ Item } & 3 & 2.07 & 1.54 & 18 & 0.84 & 1.72 & 1.25 & 12 & 0.83 & 2.42 & 1.7 & 24 & 0.82 & -0.47 \\
\hline & 5 & 2.22 & 1.69 & 20 & 0.87 & 1.77 & 1.36 & 13 & 0.88 & 2.66 & 1.86 & 28 & 0.86 & -0.55 \\
\hline & 6 & 1.87 & 1.44 & 15 & 0.8 & 1.55 & 1.1 & 9 & 0.82 & 2.17 & 1.64 & 20 & 0.77 & -0.44 \\
\hline \multicolumn{2}{|c|}{ WBIS-3 sum score } & 6.16 & 4.32 & 18 & - & 5.04 & 3.46 & 11 & - & 7.26 & 4.78 & 24 & - & -0.53 \\
\hline
\end{tabular}

$p=$ item difficulty, $d$ = Cohen's $d ; \alpha=$ Cronbach's alpha; WBIS-3 = Weight Bias Internalization Scale short form; overweight defined as body mass index $\geq 25 \mathrm{~kg} / \mathrm{m}^{2}$.

Multi-group confirmatory factor analysis (MGCFA) was conducted to investigate measurement invariance of the WBIS-3 regarding the following grouping variables: (1) gender, (2) age (under 34, 35-64, over 65 years), (3) overweight (yes/no), (4) weight status (underweight, normal weight, overweight, obesity), and (5) discrimination (yes/no). MGCFA was conducted using the R package lavaan [27]. The tested models are specified in Figure 1. As recommended by Chen [28], a change of more than 0.010 in CFI, supplemented by a change of RMSEA larger than 0.015 , was interpreted as absence of invariance.

\section{Results}

\section{Item Characteristics}

Item characteristics of the WBIS-3 are depicted in Table 2. The global mean score of the WBIS-3 in the total sample was 5.12 (SD 3.70). Item difficulty values $\left(p_{i}\right)$ ranged from 9 (item 6) to 14 (item 5). Item-rest correlations exceeded the recommended minimum (range $r_{i t}=$ 0.80 [item 6] to $r_{i t}=0.87$ [item 5]). There were substantial mean differences between men and women (Cohen's $d=-0.27$ to -0.33 ). Regarding the overweight subsample, the global mean score of the WBIS-3 was 6.16 (SD 4.32). Item difficulty ranged between 15 (item 6) and 20 (item 5); all item-rest correlation coefficients exceeded the suggested minimum (range $r_{i t}=0.80$ [item 6] to $r_{i t}=0.87$ [item 5]). At the item level, there also were considerable mean differences between men and women (Cohen's $d=-0.44$ to -0.55 ).

\section{Norms}

Tables 3 and 4 provide gender-specific norms (percentiles) for the total sample as well as for the overweight subsample.

\section{Internal Consistency}

Cronbach's alpha for the total sample was $\alpha=0.92$ and for the overweight subsample $\alpha=0.91$. 


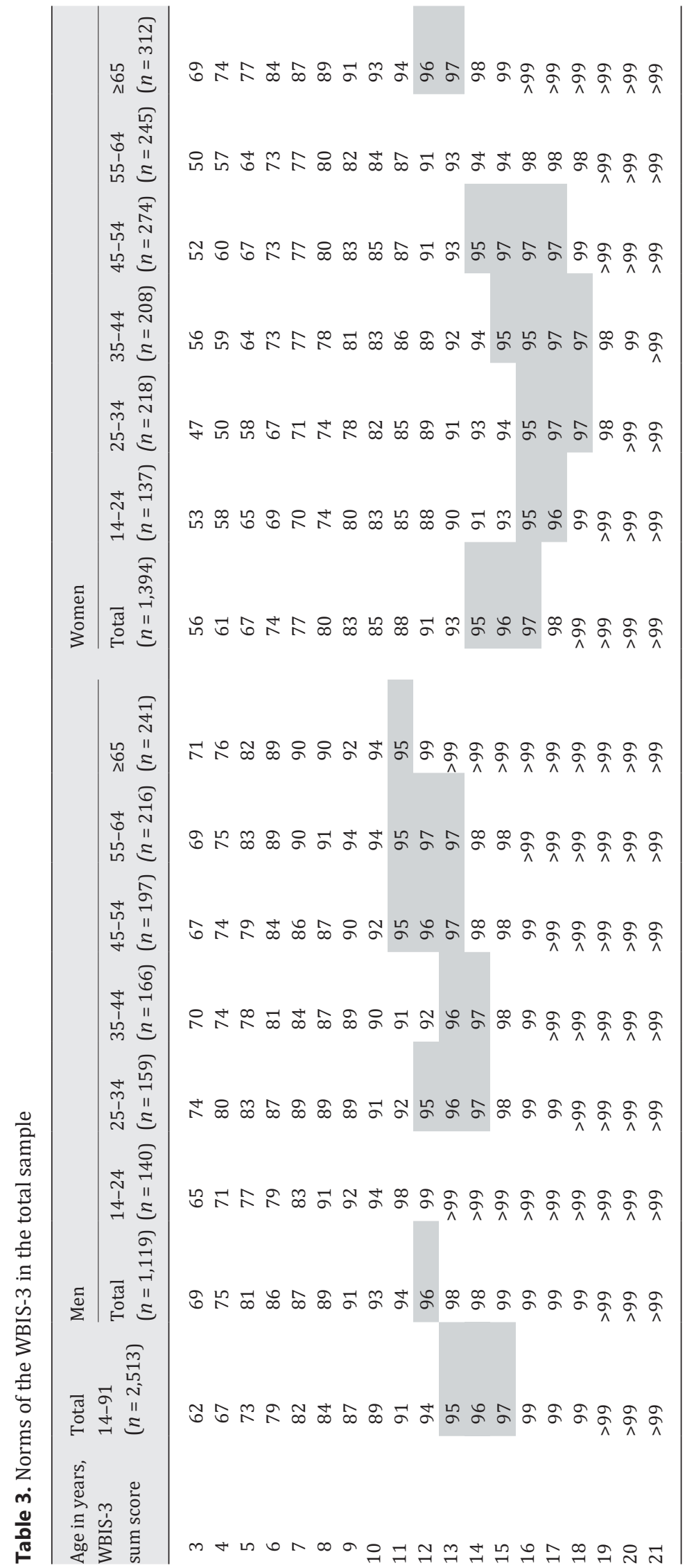




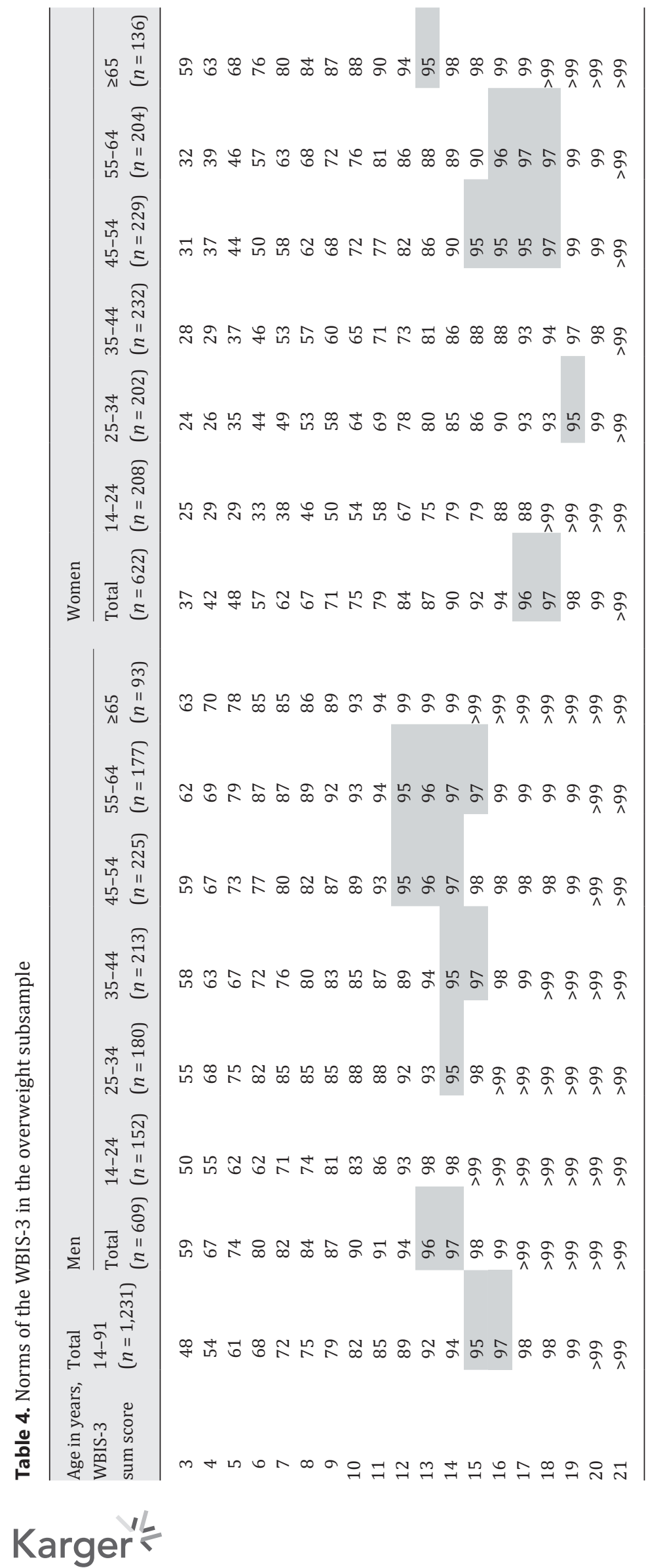


Kliem et al.: Validating the Short Form of the Weight Bias Internalization Scale

Table 5. Measurement invariance of the WBIS-3 for the total sample

\begin{tabular}{|c|c|c|c|c|c|c|c|c|}
\hline & & $\chi_{\text {scaled }}^{2}$ & df & CFI & RMSEA & $\Delta \mathrm{CFI}$ & $\triangle \mathrm{RMSEA}$ & $\begin{array}{l}\text { Measurement } \\
\text { invariance test }^{\#}\end{array}$ \\
\hline \multicolumn{9}{|c|}{ Group = gender } \\
\hline Model 0 & Weak invariance & 0.570 & 2 & 1.000 & $0.000(0.000-0.012)$ & - & - & $\checkmark$ \\
\hline Model 1 & Strong invariance & 2.010 & 4 & 1.000 & $0.000(0.000-0.019)$ & 0.000 & 0.000 & $\checkmark$ \\
\hline Model 2 & Strict invariance & 119.878 & 7 & 0.902 & $0.113(0.103-0.124)$ & -0.098 & 0.113 & $\mathrm{x}$ \\
\hline \multicolumn{9}{|c|}{ Group = overweight status } \\
\hline Model 0 & Weak invariance & 0.999 & 2 & 1.000 & $0.000(0.000-0.024)$ & - & - & $\checkmark$ \\
\hline Model 1 & Strong invariance & 1.608 & 4 & 1.000 & $0.000(0.000-0.012)$ & 0.000 & 0.000 & $\checkmark$ \\
\hline Model 2 & Strict invariance & 112.868 & 7 & 0.876 & $0.110(0.100-0.120)$ & -0.124 & 0.110 & $\mathrm{x}$ \\
\hline \multicolumn{9}{|c|}{ Group = discrimination } \\
\hline Model 0 & Weak invariance & 9.849 & 2 & 0.990 & $0.056(0.036-0.078)$ & - & - & $\checkmark$ \\
\hline Model 1 & Strong invariance & 15.222 & 4 & 0.985 & $0.047(0.032-0.064)$ & -0.05 & -0.009 & $\checkmark$ \\
\hline Model 2 & Strict invariance & 261.533 & 7 & 0.668 & $0.170(0.162-0.178)$ & -0.317 & 0.123 & $\mathrm{x}$ \\
\hline \multicolumn{9}{|l|}{ Group = age } \\
\hline Model 0 & Weak invariance & 10.067 & 4 & 0.995 & $0.043(0.024-0.062)$ & - & - & $\checkmark$ \\
\hline Model 1 & Strong invariance & 22.047 & 8 & 0.989 & $0.046(0.030-0.062)$ & -0.06 & 0.003 & $\checkmark$ \\
\hline Model 2 & Strict invariance & 40.909 & 14 & 0.979 & $0.048(0.038-0.058)$ & -0.010 & 0.02 & $\checkmark$ \\
\hline \multicolumn{9}{|c|}{ Group = weight category } \\
\hline Model 0 & Weak invariance & 11.806 & 6 & 0.993 & $0.039(0.017-0.060)$ & - & - & $\checkmark$ \\
\hline Model 1 & Strong invariance & 19.873 & 12 & 0.990 & $0.032(0.011-0.051)$ & -0.003 & -0.007 & $\checkmark$ \\
\hline Model 2 & Strict invariance & 191.924 & 21 & 0.783 & $0.114(0.105-0.122)$ & -0.107 & 0.078 & $\mathrm{x}$ \\
\hline
\end{tabular}

$\mathrm{df}=$ degrees of freedom; $\mathrm{CFI}=$ comparative fit index; $\triangle \mathrm{CFI}=$ differences between models $(0$ and 1,1 and 2$)$ regarding CFI; RMSEA = root mean square of approximation; $\triangle$ RMSEA = differences between models ( 0 and 1,1 and 2 ) regarding RMSEA. ${ }^{\#} \boldsymbol{\Delta C F I} \leq-0.010$ supplemented by $\Delta$ RMSEA $\geq \mathbf{0 . 0 1 5}$ indicates non-invariance; $\sqrt{ }$ marks invariance. All fit statistics are robust.

Table 6. Measurement invariance of the WBIS-3 for the overweight subsample

$\chi_{\text {scaled }}^{2}$ df CFI RMSEA $\quad \Delta$ CFI $\quad \triangle$ RMSEA $\begin{aligned} & \begin{array}{l}\text { Measurement } \\ \text { invariance test }\end{array} \\ & \text { in }\end{aligned}$

Group = gender

Model 0

Model 1

Model 2

Group = discrimination

Model 1

Model 2

Group = age

Model 0

Model 1

Model 2
Weak invariance

Strong invariance

Strict invariance

Weak invariance

Strong invariance

Strict invariance

Weak invariance

Strong invariance

Strict invariance

$\begin{array}{rrr}0.270 & 2 & 1.000 \\ 1.375 & 4 & 1.000 \\ 103.539 & 7 & 0.898\end{array}$

$0.000(0.000-0.000)$

$0.000(0.000-0.021)$

$0.150(0.0132-0.168)$

$0.071(0.042-0.102)$

$0.068(0.047-0.091)$

$0.212(0.196-0.227)$

$\begin{array}{lll}15.332 & 4 & 0.977\end{array}$

$\begin{array}{lll}199.931 & 7 & 0.600\end{array}$

$\begin{array}{lll}9.887 & 4 & 0.995\end{array}$

$\begin{array}{lll}19.536 & 8 & 0.989\end{array}$

$\begin{array}{lll}50.372 & 14 & 0.966\end{array}$
$0.060(0.029-0.092)$

$0.059(0.033-0.086)$

$0.080(0.063-0.096)$
$-$

0.000

0.000

$0.150 \quad \mathrm{x}$

$\begin{array}{llll}- & - & \\ - & -010 & -0.003 & \end{array}$

$-0.010 \quad-0.003$

$-0.377 \quad 0.144$

$-0.377 x$

$-$

$-0.006 \quad-0.001$

$\begin{array}{ll}-0.023 & 0.021\end{array}$

$\mathrm{df}=$ degrees of freedom; $\mathrm{CFI}=$ comparative fit index; $\triangle \mathrm{CFI}=$ differences between models $(0$ and 1,1 and 2$)$ regarding CFI; RMSEA = root mean square of approximation; $\triangle$ RMSEA $=$ differences between models $(0$ and 1,1 and 2$)$ regarding RMSEA. ${ }^{\#} \Delta \mathrm{CFI} \leq-0.010$ supplemented by $\triangle$ RMSEA $\geq 0.015$ indicates non-invariance; $\checkmark$ marks invariance. All fit statistics are robust.

\section{Measurement Invariance}

In both, the total sample as well as the overweight subsample, strong measurement invariance was confirmed regarding age, gender, discrimination status, and weight category (see Tables 5 and 6). Apart from one exception (age in the full sample), strict invariance could not be confirmed. 


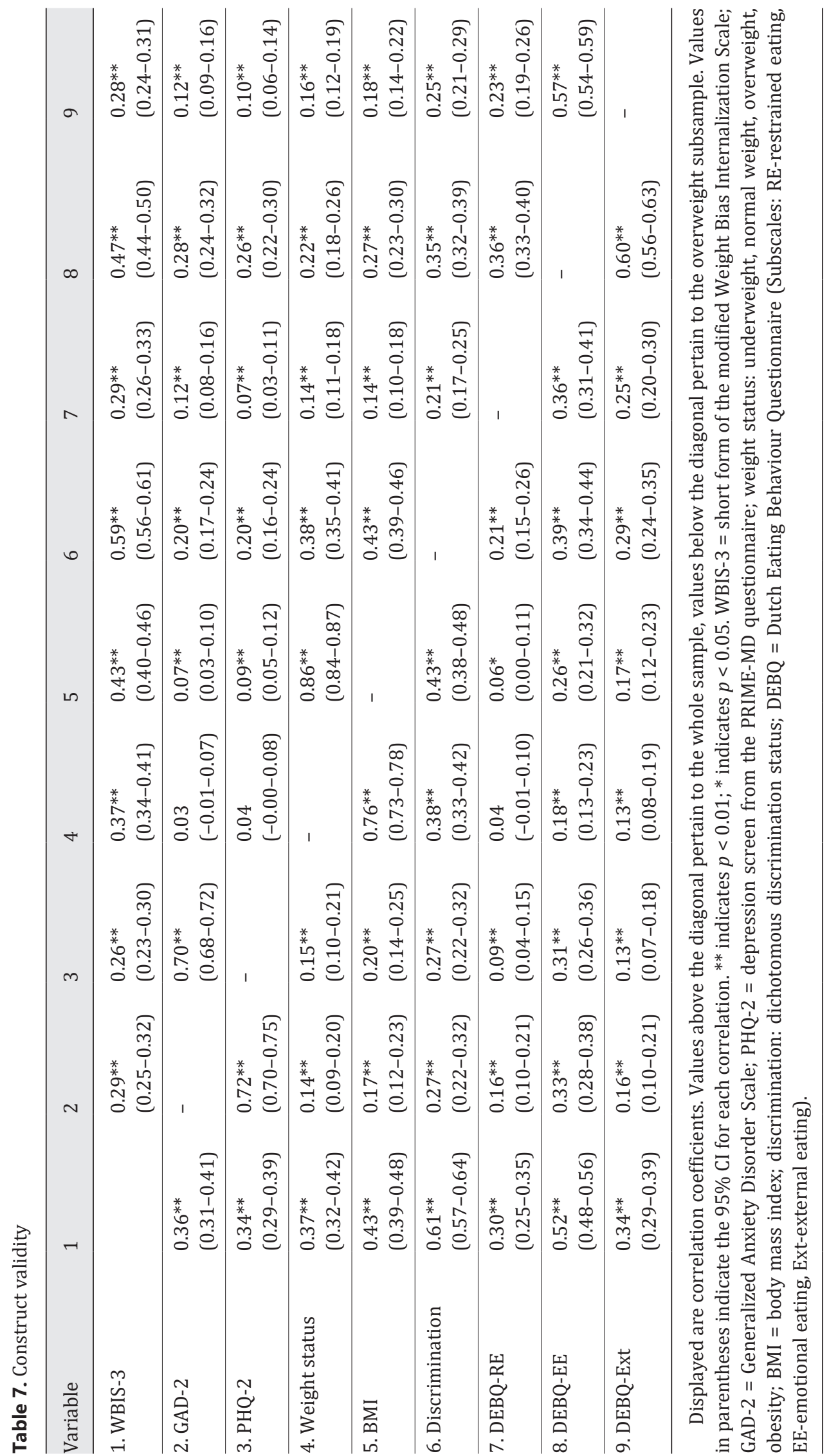


Construct Validity

Correlations between the WBIS-3 and other self-report questionnaires were significant and in the expected direction for the total sample as well as the overweight subsample (see Table 7).

\section{Discussion}

A three-item short form of the modified Weight Bias Internalization Scale [13], the WBIS-3, was constructed based on data from a large German population sample. The newly developed questionnaire was evaluated in a second independent population sample. Based on the latter, population norms were derived. Excellent internal consistency supported reliability. Evidence of strong measurement invariance by gender, age, weight status (i.e., underweight, normal weight, overweight, obese), and discrimination status was found. This allows unbiased comparison of means, correlation coefficients as well as path coefficients within structural equation modeling across groups. Furthermore, the construct validity of the WBIS-3 was confirmed by replicating theoretically derived relationships with depression, anxiety, eating behavior, and discrimination.

\section{Limitations}

First, the study relies on self-report. Without external validation it might be possible that general negative self-evaluations are responsible for the observed correlation patterns (i.e., between WBI and discrimination). Second, since the data were obtained in the German general population, comparisons with countries with differing or highly diverse cultural norms regarding weight issues might be limited. Third, as this study solely involved cross-sectional data, it neither addressed predictive validity nor test-retest reliability or longitudinal measurement invariance. Fourth, item selection was conducted based on psychometric properties obtained in a representative overweight sample using the original overweight-related wording. Although it cannot be ruled out that a different subset of items might be more appropriate for a more general purpose, there is no apparent reason to question the suitability of the chosen items.

\section{Conclusion}

With excellent psychometric properties, the WBIS-3 is suitable for research in an epidemiological framework. Given the high correlation with the WBIS full-length form, the use of the short form appears appropriate.

\section{Acknowledgements}

A.Hil. was supported by the German Federal Ministry of Education and Research (grant 01E01501). We acknowledge support from the German Research Foundation (DFG) and the Leipzig University within the program of Open Access Publishing.

\section{Statement of Ethics}

All procedures involving human participants were in accordance with the ethical standards of the institutional and/or national research committee, and with the 1964 Helsinki Declaration and its later amendments or comparable ethical standards. Written informed

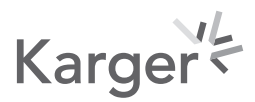


consent was obtained from each individual participating in the study. All procedures were approved by the Ethics Committee of the Medical Faculty of Leipzig University (Az.: 044-15090322015).

\section{Conflict of Interest Statement}

The authors have no conflicts of interest to declare.

\section{Funding Sources}

There are no funding sources to declare.

\section{Author Contributions}

S.K. and A.K. were responsible for data analysis and interpretation as well as the preparation of the manuscript. A.Hin. and A.K. revised the manuscript. E.B. and A.Hil. conceptualized and designed the study, reviewed and revised the manuscript. All authors had full access to the data, read, and approved the final manuscript.

\section{References}

1 Puhl RM, Andreyeva T, Brownell KD. Perceptions of weight discrimination: prevalence and comparison to race and gender discrimination in America. Int J Obes. 2008 Jun;32(6):992-1000.

2 Levy BR, Pilver CE. Residual stigma: psychological distress among the formerly overweight. Soc Sci Med. 2012 Jul;75(2):297-9.

3 Sikorski C, Spahlholz J, Hartlev M, Riedel-Heller SG. Weight-based discrimination: an ubiquitary phenomenon? Int J Obes. 2016 Feb;40(2):333-7.

4 Puhl RM, Himmelstein MS, Quinn DM. Internalizing weight stigma: prevalence and sociodemographic considerations in US adults. Obesity (Silver Spring). 2018 Jan;26(1):167-75.

5 Jackson SE. Obesity, weight stigma and discrimination. J Obes Eat Disord. 2016;2:3

6 Salsman J. Evaluating the impact of fat stigma on obesity. PsycCRITIQUES. 2012;57(16).

7 Durso LE, Latner JD. Understanding self-directed stigma: development of the weight bias internalization scale. Obesity (Silver Spring). 2008 Nov;16(Suppl 2):S80-6.

8 Cheng OY, Yam CL, Cheung NS, Lee PL, Ngai MC, Lin CY. Extended Theory of Planned Behavior on eating and physical activity. Am J Health Behav. 2019 May;43(3):569-81.

9 Alimoradi Z, Golboni F, Griffiths MD, Broström A, Lin CY, Pakpour AH. Weight-related stigma and psychological distress: A systematic review and meta-analysis. Clin Nutr. 2020 Jul;39(7):2001-13.

10 Pearl RL, Puhl RM. Weight bias internalization and health: a systematic review. Obes Rev. 2018 Aug;19(8): 1141-63.

11 Hilbert A, Baldofski S, Zenger M, Löwe B, Kersting A, Braehler E. Weight bias internalization scale: psychometric properties and population norms. PLoS One. 2014 Jan;9(1):e86303.

12 Pearl RL, Himmelstein MS, Puhl RM, Wadden TA, Wojtanowski AC, Foster GD. Weight bias internalization in a commercial weight management sample: prevalence and correlates. Obes Sci Pract. 2019 Jul;5(4):342-53.

13 Pearl RL, Puhl RM. Measuring internalized weight attitudes across body weight categories: validation of the modified weight bias internalization scale. Body Image. 2014 Jan;11(1):89-92.

14 Lillis J, Luoma JB, Levin ME, Hayes SC. Measuring weight self-stigma: the weight self-stigma questionnaire. Obesity (Silver Spring). 2010 May;18(5):971-6.

15 Hübner C, Schmidt R, Selle J, Köhler H, Müller A, de Zwaan M, et al. Comparing self-report measures of internalized weight stigma: The Weight Self-Stigma Questionnaire versus the Weight Bias Internalization Scale. PLoS One. 2016 Oct;11(10):e0165566.

16 Hayes A. A computational tool for survey shortening applicable to composite attitude, opinion, and personality measurement scales. Chicago: Routledge; 2005.

17 Kroenke K, Spitzer RL, Williams JB. The Patient Health Questionnaire-2: validity of a two-item depression screener. Med Care. 2003 Nov;41(11):1284-92. 
18 Löwe B, Wahl I, Rose M, Spitzer C, Glaesmer H, Wingenfeld K, et al. A 4-item measure of depression and anxiety: validation and standardization of the Patient Health Questionnaire-4 (PHQ-4) in the general population. J Affect Disord. 2010 Apr;122(1-2):86-95.

19 Spitzer RL. Validation and utility of a self-report version of PRIME-MD: the PHQ primary care study. Primary Care Evaluation of Mental Disorders. Patient Health Questionnaire. JAMA. 1999;282(18):1737-44.

20 Kroenke K, Spitzer RL, Williams JB, Monahan PO, Löwe B. Anxiety disorders in primary care: prevalence, impairment, comorbidity, and detection. Ann Intern Med. 2007 Mar;146(5):317-25.

21 Hinz A, Klein AM, Brähler E, Glaesmer H, Luck T, Riedel-Heller SG, et al. Psychometric evaluation of the Generalized Anxiety Disorder Screener GAD-7, based on a large German general population sample. J Affect Disord. 2017 Mar;210:338-44.

22 van Strien T, Frijters JE, Bergers GP, Defares PB. The Dutch Eating Behavior Questionnaire (DEBQ) for assessment of restrained, emotional, and external eating behavior. Int J Eat Disord. 1986;5(2):295-315.

23 Grunert SC. Ein Inventar zur Erfassung von Selbstaussagen zum Ernährungsverhalten [A questionnaire for the assesment of self-reportet eating behavior]. Diagnostica. 1989;35:167-79.

24 Hilbert A, Hübner C, Schmutzer G, Danielsdottir S, Brähler E, Puhl R. Public support for weight-related antidiscrimination laws and policies. Obes Facts. 2017;10(2):101-11.

25 van Buuren S, Groothuis-Oudshoorn K. mice: multivariate imputation by chained equations in R. J Stat Softw. 2011;45(3):1-68.

26 Baldofski S, Rudolph A, Tigges W, Herbig B, Jurowich C, Kaiser S, et al. Weight bias internalization, emotion dysregulation, and non-normative eating behaviors in prebariatric patients. Int J Eat Disord. 2016 Feb;49(2): 180-5.

27 Rosseel Y. lavaan: An R Package for Structural Equation Modeling. J Stat Softw. 2012;48(2).

28 Chen FF. Sensitivity of goodness of fit indexes to lack of measurement invariance. Struct Equ Modeling. 2007; 14(3):464-504.

29 Kromeyer-Hauschild K, Moss A, \& Wabitsch M. Referenzwerte für den Body-Mass-Index für Kinder, Jugendliche und Erwachsene in Deutschland [Reference values for the body mass index for children, young people and adults in Germany]. Adipositas-Ursachen, Folgeerkrankungen, Therapie. 2015;9(03),123-127. 